\title{
Multidrug-resistant tuberculosis: Long term follow-up of 40 non-HIV-infected patients
}

\author{
Monica Avendaño MD FRCPC, RS Goldstein MD FRCPC \\ West Park Hospital, Department of Medicine, University of Toronto, Toronto, Ontario
}

\begin{abstract}
M Avendaño, RS Goldstein. Multidrug-resistant tuberculosis: Long term follow-up of 40 non-HIV-infected patients. Can Respir J 2000;7(5):383-389.
\end{abstract}

BACKGROUND: There has been a steady increase in referrals of patients with multidrug-resistant tuberculosis (MDR-TB) who are human immunodeficiency virus (HIV) negative. Between 1986 and 1999, 40 patients were admitted to the authors' institution, eight of whom were admitted between January and June 1999. The management of such individuals is difficult. Although they are a clinically and epidemiologically important group of patients, few reports detail their management.

OBJECTIVES: To review the demographics, clinical management and long term outcome of 40 non-HIV-infected individuals with MDR-TB referred to the only specialized TB inpatient service in Ontario.

PATIENTS AND METHODS: Clinical hospital records were reviewed.

RESULTS: Twenty-one men and 19 women (mean age $41 \pm 18$ years) were admitted between January 1986 and June 1999 with MDR-TB and negative serology for HIV. Thirtyeight patients $(95 \%)$ were born outside of Canada. Twentysix patients $(65 \%)$ had a history of previous TB. All were symptomatic with productive cough and positive sputum smears for acid-fast bacilli. There was a delay of 4.5 months between the initial diagnosis of TB and the recognition of the presence of MDR-TB. Four patients (10\%) had TB resistant to isoniazid and rifampin only. Over $50 \%$ of patients had TB with additional resistance to streptomycin, and over $40 \%$ had additional resistance to ethambutol. Coexisting resistance was also found in significant numbers for pyrazinamide, ethionamide, para-aminosalicylic acid and cycloserine. Bacteriological conversion was achieved in 34 patients (85\%). Six patients underwent surgical resection for localized lung disease. Twenty-four patients completed treatment and have remained free of disease for $33 \pm 25$ months. All five patients $(12 \%)$ who died had longstanding disease before their referral.

CONCLUSIONS: MDR-TB is most frequently seen among immigrants with a previous history of TB, especially if they come from countries in which TB is highly prevalent. Outcome can be improved by a more timely recognition of MDR-TB.

Key Words: Human immunodeficiency virus-negative patients; Long term follow-up; Multidrug-resistant tuberculosis

\section{Tuberculose multirésistante : suivi à long terme de 40 patients non porteurs du VIH}

CONTEXTE: On observe une augmentation constante du nombre de patients non porteurs du virus de l'immuno-déficience humaine (VIH), qui sont dirigés en consultation pour de la tuberculose multirésistante (TMR). Entre 1986 et 1990, 40 patients ont été admis à l'établissement de l'auteur, dont huit entre janvier et juin 1999. Il s'agit de cas difficiles à traiter. Même si ces patients forment un groupe important sur les plans clinique et épidémiologique, il existe peu de rapports sur leur prise en charge. OBJECTIFS : Revoir les données démographiques, la prise en charge clinique et les résultats à long terme de 40 patients non porteurs du VIH, atteints de TMR, dirigés vers le seul service spécialisé en TB en milieu hospitalier de l'Ontario.

voir page suivante 
PATIENTS ET MÉTHODE : Passer en revue les dossiers médicaux cliniques.

RÉSULTATS : Vingt et un hommes et 19 femmes (âge moyen : $41 \pm 18$ ans) séronégatifs à l'égard du VIH ont été admis entre janvier 1986 et juin 1999 pour de la TMR. Trentehuit d'entre eux $(95 \%)$ étaient originaires de pays étrangers et $26(65 \%)$ avaient des antécédents de TB. Tous les patients présentaient une toux productive et des frottis d'expectorations positifs à l'égard des bacilles acido-résistants. Il s'était écoulé 4,5 mois entre le diagnostic initial et la reconnaissance de la TMR. Quatre patients (10\%) souffraient d'une TB résistante à l'isoniazide et la rifampine seulement. Dans plus de $50 \%$ des cas, la TB était également résistante à la streptomycine et, dans plus de $40 \%$ des cas, la maladie était aussi résistante à l'éthambutol. On a observé des cas de résistance concomitante au pyrazinamide, à l'éthionamide, à l'acide paraaminosalicylique et à la cyclosérine chez un bon nombre de patients. Il y a eu virage bactériologique chez 34 patients (85\%). Six patients ont subi une résection chirurgicale pour maladie pulmonaire circonscrite. Vingt-quatre patients ont suivi un traitement complet et sont restés sans trace de la maladie durant $33 \pm 25$ mois. Les cinq patients $(12 \%)$ qui sont morts souffraient de TB depuis longtemps avant d'être dirigés vers le centre en question.

CONCLUSION : La TMR se rencontre le plus souvent chez les immigrants ayant des antécédents de TB, surtout s'ils viennent de pays où sévit la maladie. La reconnaissance rapide de la TMR permettrait d'obtenir de meilleurs résultats.
$\mathrm{I}_{\mathrm{n}}^{\mathrm{n}}$ nfection with Mycobacterium tuberculosis remains one of the most important public health issues in the world $(1,2)$. Although tuberculosis (TB) occurs predominantly in developing countries, individuals visiting or emigrating from areas in which the incidence of TB is high affect the public health profile and the utilization of health care resources in more developed countries. Individuals most at risk for TB reside in areas in which poverty, inadequate housing and poor nutrition render them more susceptible to infection $(3,4)$. In recent years, the association between TB and human immunodeficiency virus (HIV) infection (dual infection) has been highlighted (5-7). Patients with dual infection are especially difficult to manage. If the TB is due to multidrug-resistant (MDR) bacilli, the usual approaches to treatment often fail (8-10).

Reports documenting MDR-TB have largely addressed individuals in whom dual infection was present $(11,12)$. Invariably, the prognosis was poor, with deaths often occurring within a few weeks of diagnosis (13). Less information is available when MDR-TB occurs in the absence of HIV infection. In a report of $134 \mathrm{HIV}$-negative patients with pulmonary TB resistant to isoniazid and rifampin, the mortality rate was $22 \%$ despite the fact that $56 \%$ of patients achieved bacteriological conversion and remained free of disease throughout a mean follow-up period of 51 months (14). A network of seven New York City teaching centres followed 25 HIV-negative patients with MDR-TB between 1991 and 1994, and confirmed that bacteriological conversion occurred in 17 patients (15). MDR-TB is more difficult to manage than ordinary TB, even among HIV-negative individuals. Management of such patients requires familiarity with less frequently used, second-line antituberculous drugs.

There has been a substantial increase in the number and complexity of MDR-TB patients in Ontario (population nine million). Between January 1990 and December 1999, MDR-TB was isolated in 82 cases, of which $60 \%$ occurred in the final three years of the study. In contrast, new cases of TB have remained constant at 500 new cases/year over the past 10 years. The present report describes the management and follow-up of 40 cases of MDR-TB in non-HIVinfected individuals treated between January 1986 and June 1999, representing over $45 \%$ of all new cases of MDR-TB in Ontario.

\section{PATIENTS AND METHODS}

The clinical records of 40 cases of MDR-TB admitted to a TB service between January 1986 and June 1999 were reviewed. Referrals came from community physicians, other hospitals and public health officers. The patients were referred when they failed to respond to standard combinations of anti-TB drugs, or when the drug susceptibility reports noted resistance to at least rifampin and isoniazid.

Definitions: MDR-TB was defined as TB caused by $M$ tuberculosis that was resistant to isoniazid and rifampin, with or without additional resistance to other anti-TB drugs (16). Primary MDR-TB was defined as MDR-TB with no previous history of TB, while acquired MDR-TB meant resistance acquired after previous treatment for TB. Initial MDR-TB was defined as resistance that was identified in the first isolate (including primary or undisclosed acquired MDR-TB). Bacteriological conversion was said to occur if three sets of negative cultures of three sputum specimens were obtained on three consecutive days, each set being separated by one month. Finally, relapse was defined as a positive culture for $M$ tuberculosis two years after persistently negative cultures. Clinical management: During the initial clinical assessment, special emphasis was placed on history of previous $\mathrm{TB}$, use of anti-TB medications, and compliance with prior treatment or follow-up. For non-English-speaking patients, the interview was conducted with the assistance of an interpreter. Signs of extrapulmonary involvement or associated conditions that might influence the clinical course of the MDR-TB were noted. All patients had an initial chest radiographical examination, and standard hematology and biochemistry testing. Serology for HIV was done after patients gave informed consent for the test. A psychosocial assessment was carried out shortly after admission to establish the patient's needs and to assist with discharge planning.

Early morning sputum samples were obtained on three consecutive days, being induced with inhaled saline when necessary. Bronchoscopy was performed only when a reliable sputum sample could not be obtained. All specimens were sent to the Provincial Public Health Laboratory for drug-susceptibility testing. When possible, all previous bacteriological information was retrieved.

Treatment regimens: When drug resistance was suspected, the initial regimen included at least five drugs: isoniazid, ri- 
fampin, pyrazinamide, ethambutol and streptomycin. If the details of previous treatment were available, the initial combination of drugs included at least three that the patient had not taken before; at least two of these drugs were bactericidal.

If the pattern of resistance was known, the initial regimen included at least three bactericidal drugs (two oral and one parenteral) to which the infecting organism was susceptible. Patients with TB resistant to all first-line drugs (rifampin, isoniazid, streptomycin, pyrazinamide and ethambutol) were prescribed amikacin or capreomycin, clofazimine and a fluoroquinolone (ciprofloxacin, ofloxacin or levofloxacin), plus or minus cycloserine, ethionamide and paraaminosalicylic acid. Treatment was continued for two years after bacteriological conversion.

Side effects: To avoid gastric irritation (the most common side effect), medications were dispensed with food or at bedtime. When necessary, mild antacids, antinausea medications and antiemetics were prescribed to facilitate drug tolerance. If drug toxicity occurred, all potentially toxic drugs were discontinued. If only one of the original medications could be continued, at least two others to which the organism was sensitive were added. If this was not possible, all medications were discontinued and reintroduced individually while the patient was closely monitored for side effects.

Surgery: Surgery was considered if, after a clinical response including negative cultures or a decrease in the colony count, the disease became localized with no further resolution, especially if a residual cavity was identified in the chest radiograph. Surgery was only possible if, in addition to the above findings, there was ongoing drug susceptibility. Before surgery, patients underwent bacteriological testing every four weeks and a chest radiograph every one to two months. The immediate preoperative assessment included a computed tomography scan of the chest, measurement of arterial blood gases and simple spirometry. Drugs were continued throughout the perioperative period and for two years after bacteriological conversion had been achieved.

Inpatient management: All patients remained in respiratory isolation for as long as their sputum was culture-positive for M tuberculosis. As smears became negative, partial isolation (a mask on leaving the room, restricted mobility within the hospital and no return to the community) was implemented until the cultures became negative. Pharmacological management was supplemented with intensive patient and family education. Treatment adherence was emphasized through audiovisual materials prepared in the patient's native language.

Psychosocial support was provided throughout the hospitalization phase and extended to the home phase as necessary.

Criteria for discharge: Patients were discharged following bacteriological conversion. Before the implementation of directly observed therapy (DOT), patients were trained to self-medicate. A community public health nurse supervised the patients at least once a week. Subsequently, as DOT became available in Ontario (health care provider witnesses the administration of each dose of medication), all patients were introduced to it immediately upon discharge. Patients without homes were provided assistance to secure appropriate housing.

Follow-up: All patients were seen four weeks after discharge. Subsequent visits were scheduled at two-month intervals until treatment completion, after which patients were seen at six-month intervals for a further two years and once a year thereafter. At each clinical visit, a clinical evaluation and a chest radiograph were performed, and pills were counted. Patients were assessed in the clinic by a physician and a nurse, both of whom had experience with MDR-TB.

Contact management: All cases of MDR-TB were reported to the public health service for contact tracing and screening. In Ontario, treatment of latent TB infection (positive tuberculin skin test in the absence of active disease) is not mandatory. Although tuberculin skin tests were positive in many of the contacts, treatment was frequently refused. Communitybased physicians were always advised when active cases of MDR-TB or their contacts were identified. The preference of the primary care physician was usually for the individual to be managed through the specialized centre in conjunction with public health.

\section{RESULTS}

Between January 1986 and June 1999, 40 patients (21 male, 19 female), with a mean age of $41 \pm 18$ years (range 20 to 89 years), with MDR-TB and HIV-negative serology were admitted. They represented $3.5 \%$ of all patients admitted to the TB Service and $48 \%$ of all patients in whom MDR-TB was isolated in Ontario. Thirty-one patients were admitted between January 1986 and December 1998; the last nine patients were admitted during the first six months of 1999.

Country of origin: Of the 40 patients, 38 (95\%) were born outside Canada. The two Canadian-born patients were male (aged 54 and 58 years). Both had a history of previous TB with poor compliance for treatments and follow-up. They had persistently positive sputum smears and cultures with radiologically very advanced cavitary disease. Their management had been complicated by nicotine and alcohol abuse, as well as by frequent changes of address. Multiple treatment attempts (more than six) over periods of seven and 14 years, respectively, had been unsuccessful. Resistance to first- and second-line drugs had developed.

The 38 foreign-born patients were from Vietnam $(n=11)$, China $(n=5)$, East Indies $(n=4)$, Somalia $(n=4)$, Philippines $(n=4)$, Tibet $(n=4)$, Korea $(n=3)$, Eastern Europe $(n=1)$, Ghana $(n=1)$ and Guyana $(n=1)$. When MDR-TB was diagnosed, the patient had been in Canada for 5.3 \pm 4.5 years (range one month to 17 years).

Clinical presentation: Acquired MDR-TB was identified in 26 patients (65\%) of whom two were Canadian born and 24 were born outside of Canada. Of the latter group, 22 patients gave a history of previous TB in their country of origin. In the other two patients from that group, isoniazid-resistant TB was diagnosed soon after their arrival in Canada. MDR-TB developed in these two patients because isoniazid resistance had not been considered in their treatment. In the remaining 
TABLE 1

Symptoms in patients with multidrug-resistant tuberculosis

\begin{tabular}{lc}
\hline Symptom & Number of patients (\%) \\
\hline Productive cough & $40(100)$ \\
Weight loss & $27(68)$ \\
Malaise & $27(68)$ \\
Fever & $17(42)$ \\
Hemoptysis & $17(42)$ \\
Night sweats & $11(28)$ \\
Chest pain & $8(20)$ \\
\hline
\end{tabular}

16 patients, a history of previous TB was not forthcoming. However, they did acknowledge having had contact with people with active TB, usually in refugee camps. Therefore, it could not be confidently determined whether their MDRTB was primary or acquired.

All patients were symptomatic. Their main symptoms are summarized in Table 1 . Whereas a productive cough was a universal symptom (in $100 \%$ of patients), and severe malaise $(68 \%)$ and weight loss $(68 \%)$ were frequently noted, hemoptysis, fever and night sweats occurred in fewer than half of the subjects (42\%). Pulmonary and extrapulmonary involvement were identified in eight patients (laryngeal involvement, $n=2$; cervical node involvement, $n=2$; renal involvement, $\mathrm{n}=1$; pleural involvement, $\mathrm{n}=1$; ankle and elbow joint involvement, $\mathrm{n}=1$; and knee joint involvement, $\mathrm{n}=1$ ). Associated medical conditions, identified in 18 patients, were type I diabetes mellitus (six patients), chronic obstructive pulmonary disease (five patients), chronic renal failure (two patients) and mental illness (two patients). Three patients were found to be hepatitis B carriers and one patient was 19 weeks pregnant at the time of diagnosis of MDR-TB.

Bilateral disease was seen radiographically in 34 patients, and in the cavities of 27 patients (68\%). Apical pleural thickening, parenchymal scarring and hilar retraction were seen mostly among the patients with a previous history of TB.

The time between the initial diagnosis of active TB and recognition that the disease was due to an MDR organism was $4 \pm 5$ months (range one to 24 months). In 29 patients, this delay reflected the time required to identify and test for drug susceptibility of the mycobacteria. In 11 patients, the delay occurred for other reasons. In three patients, the attending physician accepted an initial clinical response to conventional therapy and did not review drug susceptibility results. Inaccurate patient information in laboratory requisitions (misspelled name, incorrect address, false date of birth) delayed patient identification and location in five cases. Three individuals were noncompliant with follow-up and could not be located to modify treatment in a timely fashion.

Pattern of drug resistance: The patterns of drug resistance are summarized in Table 2. Four patients had TB resistant to isoniazid and rifampin only; all four were young, recent arrivals to Canada with no history of previous active disease. Susceptibility to clofazimine was tested in the isolates of 34 patients; none were resistant. In four patients, there was addi-
TABLE 2

Pattern of drug resistance in patients with multidrug-resistant tuberculosis

\begin{tabular}{lc}
\hline Drug & Number resistant/Number tested (\%) \\
\hline Isoniazid & $40 / 40(100)$ \\
Rifampin & $40 / 40(100)$ \\
Streptomycin & $21 / 40(52)$ \\
Ethambutol & $17 / 40(43)$ \\
Pyrazinamide & $8 / 33(24)$ \\
Amikacin & $1 / 25(4)$ \\
Kanamycin & $3 / 27(11)$ \\
Capreomycin & $2 / 38(5)$ \\
Ethionamide & $10 / 36(28)$ \\
Cycloserine & $3 / 18(17)$ \\
Para-aminosalicylic & $6 / 17(35)$ \\
$\quad$ acid & \\
Ciprofloxacin & $2 / 32(6)$ \\
Ofloxacin & $1 / 9(11)$ \\
Clarithromycin & $2 / 9(22)$ \\
\hline
\end{tabular}

tional resistance to one drug, most commonly streptomycin. In the remaining 32 patients, there was additional resistance to two or more drugs.

Additional resistance to clarithromycin (two patients), ciprofloxacin (two patients) and ofloxacin (one patient) was noted in four patients. Each of these four individuals had received these antibiotics from their primary care physicians. They had presented with a three- to four-week history of productive cough, fever, malaise, poor appetite and weight loss. The antibiotics had been prescribed without a radiographical or sputum examination.

Patients with acquired MDR-TB were resistant to $2.4 \pm 1.2$ additional drugs, whereas those without a history of previous treatment were resistant to $1.5 \pm 1.1$ additional drugs.

Response to treatment: All patients were admitted to hospital. Their length of stay varied widely from two months to five years (average 6.5 \pm 6.7 months). Bacteriological conversion with clinical and radiographical improvement was achieved in 34 patients (85\%). Conversion occurred after approximately six months of treatment (range two to 54 months). One patient continued to have positive cultures after one year of treatment.

Pyrazinamide and ethambutol were used when susceptibility to them was preserved. Patients with disease resistant to all of the first-line drugs (rifampin, isoniazid, streptomycin, pyrazinamide and ethambutol) received a combination of clofazimine, a fluoroquinolone, and either amikacin or capreomycin. Other drugs used in their treatment included cycloserine, ethionamide and para-aminosalicylic acid.

The most commonly used drugs were ciprofloxacin (26 patients), clofazimine (25 patients), pyrazinamide (22 patients), ethambutol (16 patients) and ethionamide (12 patients). Thirty-three patients required parenteral medication, most commonly amikacin (11 patients) and capreomycin (10 patients).

Surgery was undertaken in six patients (pneumonectomy 
in two and lobectomy in four). Four of these patients subsequently achieved bacteriological conversion, and three have remained free of disease for 3.7 years (range 19 months to six years). One patient who relapsed four years after a right upper lobectomy achieved bacteriological conversion again and appeared to be free of disease 18 months after reinstitution of medical treatment. Two patients died of overwhelming disease, two and 10 months after surgery (right upper lobectomy and pneumonectomy, respectively).

Twenty-four patients completed treatment, having received medications for $24 \pm 5.5$ months after bacteriological conversion and follow-up for a further $33 \pm 25$ months (range six months to eight years). Eight patients were still receiving treatment at the time of publication. Two patients were lost to follow-up; both had achieved bacteriological conversion and had been followed-up for eight and 11 months after discharge from hospital.

Following bacteriological conversion, nontuberculous mycobacteria were isolated from the sputum of four patients (Mycobacterium xenopi in three, Mycobacterium avium complex in one). Treatment was not modified by this finding.

Relapse: In this study, relapse was defined as a positive culture for MDR-TB two years after the patient had produced persistently negative cultures. Four patients relapsed in the present study. In three patients, the pattern of resistance was unchanged from the initial pattern of resistance. In the fourth patient, the initial pattern reflected resistance to five first-line drugs. At the time of relapse, resistance had increased to include ethionamide. Two patients reconverted and remained negative for more than two years. One patient was still on treatment at the time of publication, and one patient died six years after initial diagnosis of MDR-TB. She had had prolonged disease in her country of origin and several unsuccessful attempts at self-treatment.

Mortality: Five patients died $7 \pm 5$ years (range 1.5 to 14 years) after the initial diagnosis of MDR-TB. All deaths were directly related to the MDR-TB. At the time of death, the infecting organism was resistant to a minimum of seven drugs. Death from massive hemoptysis occurred in two patients, with the other three patients succumbing to overwhelming disease.

\section{DISCUSSION}

Although patients with MDR-TB challenge our medical and public health services, most improve clinically and, provided that their management is carefully supervised, they also undergo bacteriological conversion (17). A well-structured follow-up ensures that the patient completes treatment.

In the absence of dual infection (MDR-TB and HIV), the major risk factor for the presence of MDR-TB in the patients in this study was a history of previous TB (65\% of cases). This has been documented in previous reports (18). A history of previous TB was present in only $3 \%$ of our patients with susceptible TB.

Most of the individuals with TB who were referred to us were born outside Canada. Ninety-five per cent of patients with MDR-TB had immigrated to Canada compared with $80 \%$ of those with drug-susceptible TB. In Southern Ontario, referral of an immigrant with a history of previous TB heightens our awareness of the possibility of the TB being MDR. This differs from the risk factors for MDR-TB encountered in New York city in 1993 (19), which included, in addition to previous TB infection, HIV infection and intravenous drug use. During the period of time covered in this report, only six cases of MDR-TB had dual infection; they comprised $13 \%$ of all our cases of MDR-TB.

In contrast with our patients who were born outside Canada, the two born in Canada had histories of chronic alcohol abuse, inadequate housing and poor nutrition. Treatment had been limited by noncompliance, and both patients died. Although a similar psychosocial history is well recognized among Canadian-born patients with drug-susceptible $\mathrm{TB}$, there were important differences in their histories of TB (over 10 years compared with less than two years for those with susceptible TB) and in the number of treatment attempts (six attempts at treatment compared with one or two at the most in those with drug-susceptible TB).

All patients with MDR-TB referred to our service are admitted. We maintain isolation measures for as long as patients are infectious $(20,21)$. They are discharged only after bacteriological conversion has occurred. Treatment is continued in the community with DOT (22-25). In addition, the patients are followed-up by frequently scheduled visits to the TB clinic. By doing so, we try to promote compliance with treatment and reduce the chances of MDR-TB being spread within the community.

Our initial drug prescription included very aggressive combinations of antituberculous agents to reduce the possibility of further drug resistance. We always included a fluoroquinolone. The fluoroquinolones have emerged as useful agents for treating MDR-TB. Our experience that they are well tolerated for extended periods with few side effects is in keeping with that of other reports (26-29). Unfortunately, resistance to them has been documented (30). In our study, three patients presented with fluoroquinolone resistance, all of them having received these antibiotics needlessly for what was thought to have been a bacterial respiratory tract infection. Given the extent to which such antibiotics are prescribed in the community, such resistance is likely to increase.

Clofazimine has also proved to be a useful medication (31). Clofazimine susceptibility was tested in the isolates from our last 34 patients; none showed resistance to it. Clofazimine is well tolerated for extended periods. The side effect of skin pigmentation fades after the drug has been discontinued.

The advantages of managing individuals with MDR-TB in a specialized centre include access to adequate respiratory isolation, good laboratory support, assured drug supply, access to an experienced multidisciplinary team and wellestablished links with Public Health. Future management will be assisted by the routine analysis of the restriction fragment length polymorphism, which will facilitate identification of case clusters as well as provide a better understanding 
of transmission of MDR-TB. To date, the restriction fragment length polymorphism analysis has not been widely available.

Treatment is often lengthy. While the patients remain infectious, close supervision by staff with expertise in managing complex cases is invaluable. In addition to the ongoing medical issues, the environment must be sensitive to the stresses of prolonged isolation, especially in those who are new to the country. The problems are compounded if the individual is the breadwinner. Some individuals fear the social stigma of TB, the diagnosis of which creates a major stress. Accurate communication and social work services are required while the patient is still in the hospital, as well as during the subsequent reintegration into the community. Compliance is enhanced by patient and family education, often using materials written in the patient's own language.

Over the past five years, physicians have become more aware of the risk of MDR-TB; as a result, most patients are now referred before the initiation of pharmacotherapy. This change has enabled a timely implementation of proper isolation measures and the initiation of treatment with a combination of drugs that minimize the risk of further drug resistance. MDR-TB is now diagnosed sooner $(2.3 \pm 3.7$ months compared with 5.5 \pm 5.2 months after initial diagnosis of TB). All five deaths in the present study occurred in patients referred between 1986 and 1993. The histories of these five patients included longstanding disease accompanied by multiple attempts at treatment. Inappropriate combinations of medications together with poorly structured follow-up led to the development of progressively more resistant organisms and overwhelming disease.

Once the sputum cultures became consistently negative, the finding of mycobacteria in the sputum smears of four patients, in the absence of either clinical or radiological evidence

\section{REFERENCES}

1. World Health Organization (WHO) Report on The Tuberculosis Epidemic, Annual Report. Geneva: WHO, 1995.

2. Raviglione MC, Snider DE Jr, Kochi A. Global epidemiology of tuberculosis. Morbidity and mortality of a worldwide epidemic. JAMA 1995;273:220-6.

3. Hudelson P. Gender differentials in tuberculosis: The role of socio-economic and cultural factors. Tuber Lung Dis 1996;77:391-400.

4. Tuberculosis and social class. Tubercle 1979;60:191-3.

5. Daley CL, Small PM, Schecter GF, et al. An outbreak of tuberculosis with accelerated progression among persons infected with the human immunodeficiency virus. An analysis using restriction-fragment-length polymorphisms. N Engl J Med 1992;326:231-5.

6. Barnes PF, Bloch AB, Davidson PT, Snider DE Jr. Tuberculosis in patients with human immunodeficiency virus infection. N Engl J Med 1991;324:1644-50.

7. Barnes PF, Le HQ, Davidson PT. Tuberculosis in patients with HIV infection. Med Clin North Am 1993;77:1369-90.

8. Farga V. Tratamiento de la tuberculosis pulmonar resistente. Enferm Respir Cir Torac 1987;3:195-9.

9. Neville K, Bromberg A, Bromberg R, Bonk S, Hanna BA, Rom WN. The third epidemic - multidrug resistant tuberculosis. Chest 1994;105:45-8.

10. Weltman AC, DiFerdinando GT Jr, Washko R, Lipsky WM. A death associated with therapy for nosocomially acquired multidrug resistant tuberculosis. Chest 1996;110:279-81.

11. Fischl MA, Uttamchandani RB, Daikos GL, et al. An outbreak of of reactivation, likely reflected the presence of nontuberculous mycobacteria. We do not recommend that treatment be changed on the basis of smear results alone unless cultures and clear identification are available. Vidal et al (32) reported the one-year follow-up of 453 patients with drugsusceptible TB after bacteriological conversion. Acid-fast bacilli were observed in the sputum of 10 patients $(2.2 \%)$. They were attributed to nonviable bacilli in eight cases and to nontuberculous mycobacteria in two cases. Given the difficulty of establishing an effective drug regimen against MDR-TB, treatment should not be modified without careful consideration of the potential for additional drug resistance.

Ironically, many years after antituberculous medications rendered them obsolete, surgical approaches to managing MDR-TB have re-emerged as an option (33). Lung resection was possible in six of our patients, with an excellent result in four of them. The two patients who died (two months and 11 months after surgery) had had MDR TB for 11 and six years, respectively.

\section{CONCLUSIONS}

MDR-TB, even in non-HIV-infected patients, remains a serious challenge for the health care system. Its management requires expertise and familiarity with the appropriate use of all available anti-TB antibiotics. We described the multidisciplinary management of 40 cases of MDR-TB in non-HIV-infected individuals at a specialized centre. Bacteriological conversion was achieved in $85 \%$ of cases. Given that we continue to receive immigrants from countries where the prevalence of MDR-TB is high and that disease can develop several years after immigration, it is likely that MDR-TB will continue to be a challenge in Canada. Immigrants who present with an abnormal chest radiograph and a history of previous $\mathrm{TB}$ are especially at risk of having MDR-TB.

tuberculosis caused by multiple-drug-resistant tubercle bacilli among patients with HIV infection. Ann Intern Med 1992;117:177-83.

12. Busillo CP, Lessnau KD, Sanjana V, et al. Multidrug resistant Mycobacterium tuberculosis in patients with human immunodeficiency virus infection. Chest 1992;102:797-801.

13. Fischl MA, Daikos GL, Uttamchandani RB, et al. Clinical presentation and outcome of patients with HIV infection and tuberculosis caused by multiple-drug-resistant bacilli. Ann Intern Med 1992:117:184-90.

14. Goble M, Iseman MD, Madsen LA, Waite D, Ackerson L, Horsburgh CR Jr. Treatment of 171 patients with pulmonary tuberculosis resistant to isoniazid and rifampin. N Engl J Med 1993;328:527-32.

15. Telzak EE, Sepkowitz K, Alpert P, et al. Multidrug-resistant tuberculosis in patients without HIV infection. N Engl J Med 1995;333:907-11.

16. Kent JH. The epidemiology of multidrug-resistant tuberculosis in the United States. Med Clin North Am 1993;77:1391-409.

17. Park SK, Kim CT, Song SD. Outcome of chemotherapy in 107 patients with pulmonary tuberculosis resistant to isoniazid and rifampin. Int J Tuberc Lung Dis 1998;2:877-84.

18. Barnes PF. The influence of epidemiologic factors on drug resistance rates in tuberculosis. Am Rev Respir Dis 1987;136:325-8.

19. Frieden TR, Sterling T, Pablos-Mendez A, Kilburn JO, Cauthen GM, Dooley SW. The emergence of drug resistant tuberculosis in New York City. N Engl J Med 1993;328:521-6.

20. Friedman CR, Stoeckle MY, Kreiswirth BN, et al. Transmission of 
multidrug-resistant tuberculosis in a large urban setting. Am J Respir Crit Care Med 1995;152:355-9.

21. Classen CN, Warren R, Richardson M, et al. Impact of social interactions in the community on the transmission of tuberculosis in a high incidence area. Thorax 1999;54:136-40.

22. Iseman MD, Cohn DL, Sbarbaro JA. Directly observed treatment of tuberculosis. We can't afford not to try it. N Engl J Med 1993;328:576-8

23. Frieden TR, Fujiwara PI, Washko RM, Hamburg MA. Tuberculosis in New York City - Turning the tide. N Engl J Med 1995;333:229-33.

24. Chaulk CP, Moore-Rice K, Rizzo R, Chaisson RE. Eleven years of community-based directly observed therapy for tuberculosis. JAMA 1995;274:945-51

25. Weis SE, Slocum PC, Blais FX, et al. The effect of directly observed therapy on the rates of drug resistance and relapse in tuberculosis. N Engl J Med 1994;330:1179-84.

26. Tsukamura M, Nakamura E, Yoshii S, Amano H. Therapeutic effect of a new antibacterial substance ofloxacin (DL8280) on pulmonary tuberculosis. Am Rev Respir Dis 1985;131:352-6.

27. Berning SE, Madsen L, Iseman MD, Peloquin CA. Long-term safety of ofloxacin and ciprofloxacin in the treatment of mycobacterial infections. Am J Respir Crit Care Med 1995;151:2006-9.

28. Peloquin CA, Berning SE, Madsen L, Iseman MD. Ofloxacin and ciprofloxacin in the treatment of mycobacterial infections: development of resistance and drug interactions. J Infect Dis Pharmacother 1995;1:45-65.

29. Kaplan JA, Krieff DM. Quinolones for the treatment and prophylaxis of tuberculosis. Ann Pharmacother 1996;30:1020-2.

30. Sullivan EA, Kreiswirth BN, Palumbo L, et al. Emergence of fluoroquinolone-resistant tuberculosis in New York City. Lancet 1995;345:1148-50.

31. Jagannath C, Reddy MV, Kailasam S, O'Sullivan JF, Gangadharam PR. Chemotherapeutic activity of clofazimine and its analogues against Mycobacterium tuberculosis: in-vitro, intracellular and in-vivo studies. Am J Respir Crit Care Med 1995;151:1083-6.

32. Vidal R, Martin-Casabona N, Juan A, Falgueras T, Miravitlles M. Incidence and significance of acid-fast bacilli in sputum smears at the end of antituberculous treatment. Chest 1996;109:1562-5.

33. Iseman MD, Madsen L, Goble M, Pomerantz M. Surgical intervention in the treatment of pulmonary disease caused by drug-resistant Mycobacterium tuberculosis. Am Rev Respir Dis 1990;141:623-5. 


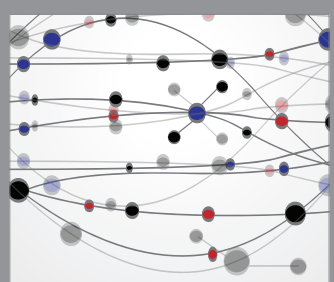

The Scientific World Journal
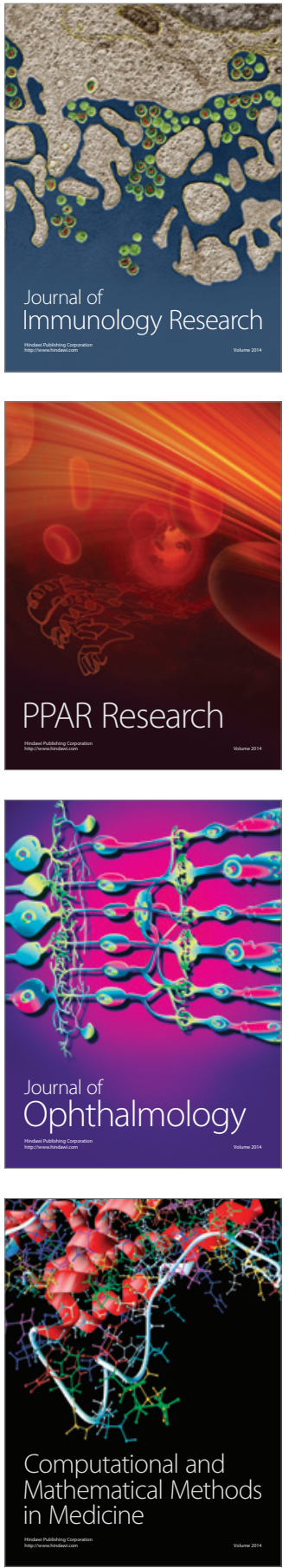

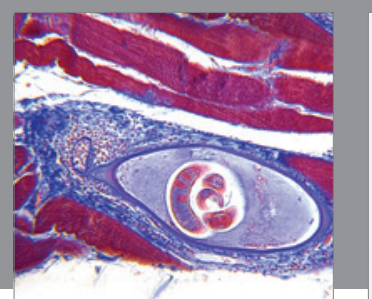

Gastroenterology Research and Practice

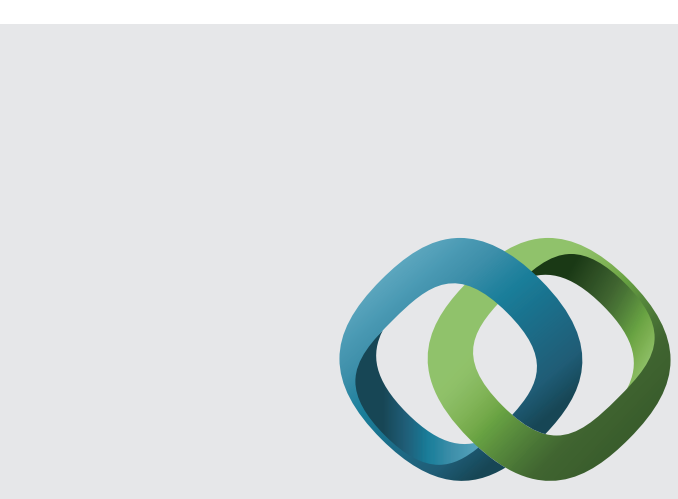

\section{Hindawi}

Submit your manuscripts at

http://www.hindawi.com
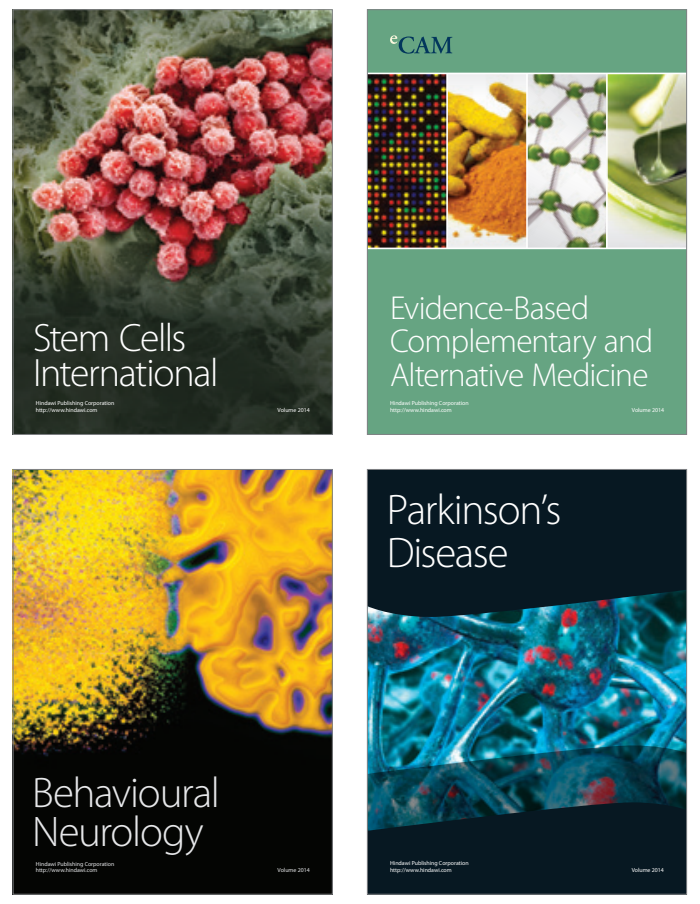
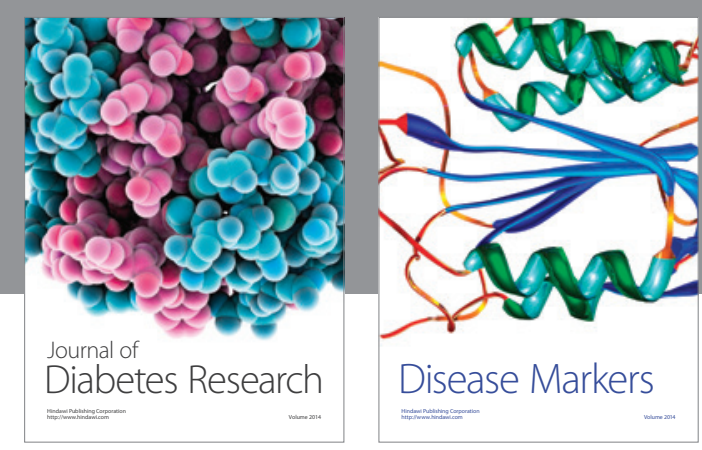

Disease Markers
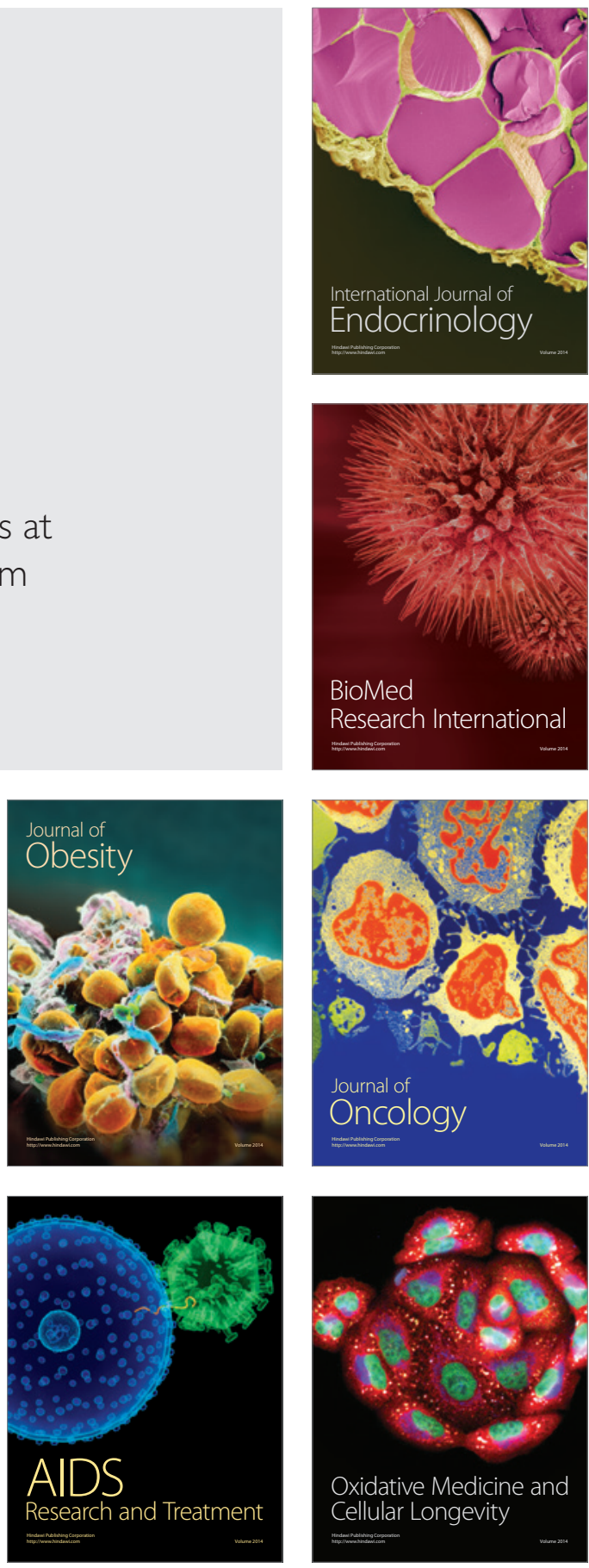